\title{
MODEL PENGEMBANGAN KAWASAN TRANSMIGRAN, KECAMATAN WAPLAU, KABUPATEN BURU, PROVINSI MALUKU
}

\author{
Achmad Tjachja Nugraha, Sumarna Hasan, Yuliana Samantha
}

\begin{abstract}
ABSTRAK
Tujuan penelitian adalah Mengetahui model pengembangan kawasan transmigran, Menghitung optimalisasi beban model penempatan transmigran dalam model pengembangan kawasan transmigrasi, Menyusun pengembangan pertanian model usaha transmigran, Menyusun penanganan dampak model. Metode yang digunakan dalam penelitian ini adalah Metode Penelitian Survey. Proses penyusunan Model Pengembangan Kawasan Transmigrasi di daerah Kecamatan Waplau Kabupaten Buru Provinsi Maluku. Jenis data primer yang dikumpulkan adalah data kelembagaan, harga pasar dan aspirasi masyarakat yang berkembang di lokasi studi Kabupaten Buru Provinsi Maluku. Jumlah sampel yang diambil sebanyak 30 responden dari 3 desa, yaitu Desa Samalagi, Desa Waera dan Desa Waplau Kecamatan Waplau. Kesimpulan dari penelitian ini sebagai berikut: (1) Karakteristik model yang meliputi aksesibilitas lokasi, kondisi fisik lahan, dan kondisi sumber daya air tercatat memberikan suatu gambaran kemampuan sumberdaya alam dalam menunjang pengembangan kawasan transmigrasi di Kabupaten Buru, (2) Berkaitan dengan Optimalisasi Model Penempatan Transmigran Dalam Model Pengembangan Kawasan Transmigras, maka rencana yang tepat peruntukan daya tampung ditentukan oleh kebutuhan pengembangan bagi pemukiman transmigrasi. Alokasi Lahan per KK adalah 2,00 Ha dengan perincian Lahan Pekarangan $(L P)=0,25 \mathrm{Ha}$, Lahan Usaha I (LU I) = 0,75Ha dan Lahan Usaha II (LU II) = 1,00 Ha. maka dapat dibentuk satuan pemukiman dengan daya tampung sebesar 300 KK, (3) Pengembangan Pertanian Model Usaha Transmigrasi, dapat dilakukan dengan prioritas dalam mengoptimalkan lahan pertanian meliputi Lahan Pekarangan (LP) seluas 0,25 hektar, Lahan Usaha I (LU I) seluas 0,75 hektar, Lahan Usaha II (LU II) seluas 1,00 hektar, (4) Berkaitan dengan penanganan model, perlu dilakukan upaya alternatif tindakan terhadap dampak penting hipotetik.
\end{abstract}

Kata kunci: pengembangan area, pendapata, model, sumber daya, transmigrasi 


\begin{abstract}
The research objective is Knowing transmigration area development model, Counting optimization of load placement model in the model transmigration transmigration area development, agricultural development Develop business models migrants, Develop impact management models. The method used in this research is the Survey Research Methods. The process of drafting model in the area of Transmigration Area Development District of Buru Waplau Maluku province. Type of primary data is data institutional, market prices and the growing aspirations of the people in the study area Buru Regency of Maluku province. Samples are taken by 30 respondents from the three villages, namely Samalagi, Waera village and sub-district village Waplau Waplau. The conclusion of this study as follows: (1) characteristics of models that include site accessibility, the physical condition of the land, and the condition of water resources listed provides an overview of the ability of natural resources to support the development of transmigration areas in Buru, (2) In connection with the Optimization Model Placement Transmigran In the Model Area development Transmigras, then the right plan capacity allocation is determined by the need for the development of transmigration settlement. Allocation of land per household is 2.00 ha with details Land courtyard $(L P)=0.25 \mathrm{Ha}$, Land Enterprises $I(L U$ I) $=0,75 \mathrm{Ha}$ and Land Enterprises II $(L U$ II $)=1.00 \mathrm{Ha}$. it can be formed residential units with a capacity of 300 KK, (3) the Agricultural Development Business Model Transmigration, take priority in optimizing agricultural land includes land courtyard (LP) covering an area of 0.25 hectares, Land Enterprises I ( LU I) covering 0 , 75 hectares, Land Enterprises II (LU II) covering an area of 1.00 hectares, (4) in connection with the handling of the model, efforts should be made of alternative measures against significant impacts hypothetical.
\end{abstract}

Keywords: development area, pendapata, models, resources, transmigration

\section{PENDAHULUAN}

\section{Latar Belakang}

Dalam era otonomi daerah, program transmigrasi diharapkan dapat memberikan suatu harapan baru dalam memanfaatkan sumberdaya alam dan sumberdaya manusia yang lebih komprehensif. Permasalahan yang sering timbul terhadap pelaksanaan pembangunan transmigrasi ini disebabkan oleh kurang terpadunya antar lintas sektor terkait dalam penanganan transmigrasi.
Dalam implementasinya tentang transmigrasi, maka pengembangan kawasan transmigrasi dirasakan cukup penting. Menurut Undang -Undang Republik Indonesia Nomor : 29 tahun 2009, Kawasan transmigrasi terdiri dari Wilayah Pengembangan Transmigrasi (WPT) yang membentuk pusat pertumbuhan baru dan Lokasi Permukiman Transmigrasi (LPT) yang mendukung pertumbuhan yang sudah ada atau yang sedang berkembang. Secara 
hirarki kewilayahan, WPT atau LPT terdiri dari SKP-SKP (Satuan Kawasan Pengembangan) dan SKP terdiri dari SP-SP (Satuan Permukiman).

Dalam implementasinya kebijakan transmigrasi diarahkan pada tiga hal pokok yaitu : (1) Penanggulangan kemiskinan yang disebabkan oleh ketidak-berdayaan penduduk untuk memperoleh tempat tinggal yang layak; (2) Memberi peluang berusaha dan kesempatan kerja; (3) Memfasilitasi pemerintah daerah dan masyarakat untuk melaksanakan perpindahan penduduk. Namun demikian dalam implementasinya mendapatkan berbagai kendala. Model pengembangan transmigrasi yang komprehensif merupakan salah satu terobosan. Penekanan pada optimalisasi sumberdaya alam memberikan suatu gambaran yang lain tentang transmigrasi.

\section{Identifikasi Masalah}

Berdasarkan uraian pada latar belakang penelitian ini, maka dapat diidentifikasikan masalahnya sebagai berikut :

1. Bagaimanakah karakteristik model pengembangan kawasan transmigrasi.

2. Bagaimanakah optimalisasi beban model penempatan transmigran dalam model pengembangan kawasan transmigrasi.

3. Bagaimanakah pengembangan usaha yang akan dilaksanakan oleh transmigran.

4. Bagaimanakan penanganan dampak model

\section{Tujuan Penelitian}

Adapun tujuan penelitian antara lain :

1. Mengetahui model pengembangan kawasan transmigran.

2. Menghitung optimalisasi beban model penempatan transmigran dalam model pengembangan kawasan transmigrasi

3. Menyusun pengembangan pertanian model usaha transmigran

4. Menyusun penanganan dampak model

\section{Kegunaan Penelitian}

Hasil penelitian ini diharapkan dapat memberikan kegunaan praktis maupun teoritis bagi pengembangan ilmu, khususnya: masyarakat calon peserta transmigrasi, pemerintah/instansi terkait, dan kalangan akademis, sebagai bahan pustaka guna pengembangan ilmu dan penelitian selanjutnya.

\section{Pendekatan Masalah}

Transmigrasi sebagai model pembangunan komunitas masyarakat mempunyai tiga sasaran pokok. Pertama, meningkatkan kemampuan dan produktivitas masyarakat transmigrasi (transmigrasi dan masyarakat sekitar permukiman transmigrasi). Kedua, membangun kemandirian (transmigran dan masyarakat sekitar permukiman transmigrasi), dan ketiga, mewujudkan integrasi di permukiman transmigrasi, sehingga ekonomi dan sosial budaya mampu tumbuh dan berkembang secara berkelanjutan.)

Esensi dari ketiga sasaran tersebut diharapkan dapat membangun komunitas masyarakat melalui upaya pemberdayaan 
dan pengembangan potensi sumberdaya wilayah dan pengarahan perpindahan penduduk. Perpindahan transmigrasi merupakan suatu profesi pemberdayaan masyarakat melalui perpindahan dari suatu daerah untuk menetap di Wilayah Pengembangan Transmigrasi (WPT) atau Lokasi Permukiman Transmigrasi (LPT). Perpindahan transmigrasi mengandung dua maksud, pertama, agar penduduk yang pindah memperoleh tempat tinggal, tempat bekerja, tempat berusaha yang memberikan sumber pendapatan tetap, dan kedua, agar daerah yang didata terpenuhi kebutuhannya sehingga dapat tumbuh dan berkembang menjadi lebih produktif, dinamis dan harmonis.

Transmigrasi memegang peranan yang sangat penting bagi berhasilnya usahausaha pembangunan. Transmigrasi selain mengurangi kepadatan penduduk didaerahdaerah tertentu, juga memperluas landasan bagi kegiatan-kegiatan pembangunan sektor-sektor lain, khususnya sektor pertanian. Disamping itu, transmigrasi juga menunjang usaha-usaha pembangunan daerah yang relative masih terbelakang.

Paradigma baru transmigrasi tidak sekadar memindahkan penduduk dari daerah yang padat penduduk ke daerah yang masih kekurangan penduduk. Lebih dari itu, transmigrasi menjadi cara bagi masyarakat untuk meningkatkan kesejahteraan hidupnya, sekaligus sebagai usaha membangun ketahanan pangan (Suparno, 2006). Proses perpindahan transmigrasi, paling tidak akan melibatkan dua Pemerintah Daerah yang akan bekerjasama. Pihak pertama yaitu Pemerintah Daerah
Tujuan, memiliki tanggungjawab dan hak atas beberapa hal yaitu (1) menyediakan tempat tinggal. tempat bekerja dan tempat berusaha, (2). memberikan pelayanan dan pembinaan agar kehadiran transmigran didaerahnya dapat tumbuh dan berkembang secara wajar, seimbang dan hidup serasi dengan penduduk setempat, dan (3). memilih kualitas dan menentukan kuantitas masyarakat yang akan datang di daerahnya. Sedangkan pihak ke dua yaitu Pemerintah Daerah Pengirim memiliki tanggungjawab dan hak atas berapa hal, yaitu (1). menyediakan sumberdaya manusia sesuai dengan kualitas dan kuantitas yang diperlukan bagi Pemerintah Daerah Tujuan, (2). Memberikan Pelayanan dalam proses perpindahan, dan (3) memilih dan menentukan lokasi tujuan sesuai dengan kompentensi yang dimiliki masyarakatnya.

Peran masing-masing pihak dalam proses perpindahan transmigrasi, maka dalam proses penyusunan model pengembangan perlu melibatkan kedua pihak secara bersama dengan mediasi dan fasilitasi Pemerintah Pusat, dimana model pengembangan daerah transmigrasi dimaksud adalah sebagai berikut :

1. Berdasarkan kebutuhan dan potensi sumberdaya yang dimiliki,

2. Kawasan atau lokasi tersebut ditawarkan kepada Pemerintah daerah Pengirim yang dikehendaki untuk melaksanakan kerjasama.

3. Proses penawaran tersebut dapat dilakukan secara langsung dengan daerah yang diinginkan

4. Penawaran secara langsung dan mediasi Pemerintah Pusat 
5. Dalam hal proses kerjasama perpindahan transmigrasi dilaksanakan dengan sharing biaya dekonsentrasi.

\section{METODE PENELITIAN}

\section{Tempat dan Waktu Penelitian}

Penelitian ini dilakukan di Wilayah Desa Samalagi Kecamatan Waplau Kabupaten Buru Provinsi Maluku. Letak geografis lokasi studi berada di $2^{\circ} 47^{\prime} 15^{\prime \prime}$ $2^{\circ} 49^{\prime} 45^{\prime \prime}$ lintang selatan 126 47'30" 126 50'00" Bujur Timur. Kegiatan penelitian dilaksanakan mulai dari bulan Mei 2014 sampai dengan bulan Juli 2014.

\section{Teknik Penelitian}

Teknik yang digunakan dalam penelitian ini adalah teknik metode survey. Penelitian survey menggunakan suatu bagan kerja untuk menggariskan desain penelitiannya. Bagan kerja itu dimulai dengan sasaran-sasaran survey, pencatatan setiap langkah yang hendak diambil, dan diakhiri dengan laporan akhir (Kerlinger, 2004).

\section{Pendekatan Studi}

Proses penyusunan Model Pengembangan Kawasan Transmigrasi di daerah Kecamatan Waplau Kabupaten Buru Provinsi Maluku melalui 4 proses yaitu : Tahap Persiapan, Survai Lapangan, serta Penyusunan Hasil Penelitian..

\section{Metode Pengumpulan Data}

Pengumpulan data adalah suatu proses pengadaan data primer dan sekunder untuk keperluan penelitian. Jenis data primer yang dikumpulkan adalah data kelembagaan, harga pasar dan aspirasi masyarakat yang berkembang di lokasi studi Kabupaten Buru Provinsi Maluku. Jumlah sampel yang diambil sebanyak 30 responden dari 3 desa, yaitu Desa Samalagi, Desa Waera dan Desa Waplau Kecamatan Waplau. Sedangkan data sekunder merupakan data yang diperoleh dalam bentuk sudah jadi yaitu diolah dan disajikan oleh pihak lain, seperti Monografi Desa Samalagi, Kecamatan Waplau Dalam Angka, serta yang lainnya.

\section{Teknik Analisis}

Berdasarkan identifikasi masalah, maka data yang akan dikumpulkan akan dianalisis sebagai berikut :

1. Mengetahui kondisi lokasi studi, dianalisis dengan cara deskriptif eksploratif, berdasarkan temuantemuan dilapangan, hasil wawancara dengan responden dan data lahan yang tersedia.

2. Mengetahui daya tampung, dianalisis dengan cara deskriptif eksploratif, berdasarkan perbandingan antara ketersediaan lahan dan alokasi per KK.

3. Mengetahui penerimaan, biaya dan pendapatan, dianalisis secara deskriptif dengan menggunakan rumus biaya dan pendapatan dihitung dengan cara :
a) Biaya Total = Biaya Tetap
+ Biaya Variabel $=\mathrm{TC}=\mathrm{FC}+\mathrm{VC}$
b) Penerimaan $=$ Jumlah Produk x Harga Jual $=\mathrm{R}=\mathrm{Q} \times \mathrm{P}$
c) Pendapatan $=$ Penerimaan- Biaya Total $=\mathrm{I}=\mathrm{R}-\mathrm{C}$




\section{GAMBARAN UMUM LOKASI STUDI}

Berdasarkan letak administratifnya Model Pengembangan Kawasan Transmigrasi berada di Kecamatan Waplau desa Samalagi, Kabupaten Buru, Provinsi

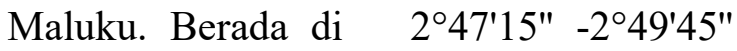
lintang selatan $126^{\circ} 47^{\prime} 30^{\prime \prime} \quad-126^{\circ} 50^{\prime} 00^{\prime \prime}$ Bujur Timur. Dimana secara fisik lokasi studi dibatasi oleh Laut Seram/Desa Samalagi, Areal Hutan Desa Samalagi, Desa Waeura dan Desa Namsina.

Aksesibilitas dan pencapaian menuju lokasi model pengembangan studi dari Ibukota Provinsi Ambon ke Kabupaten Pulau Buru ditempuh melalui dua alternatif yaitu menggunakan pesawat terbang dengan waktu tempuh 30 menit dan menggunakan kapal laut dengan waktu tempuh lebih kurang 7 jam (kapal ferry). Dari Ibukota kabupaten Namlea untuk manuju Kecamatan Waplau menggunakan mobil/Motor selama lebih kurang 45 menit dengan jarak 35KM (Jalan Kabupaten).

Selain itu secara umum, wilayah Kabupaten Buru memiliki iklim tropis dan iklim musim, karena Kabupaten Buru merupakan daerah kepulauan yang dikelilingi oleh lautan yang luas, sehingga sangat dipengaruhi oleh keadaan laut dan seirama dengan iklim musim yang berlangsung di wilayah ini. Kabupaten Buru mempunyai tiga musim yaitu musim utara, barat dan musim timur atau musim selatan dan diselingi dua kali masa peralihan atau pancaroba. Iklim daerah Kabupaten Buru termasuk iklim tropis basah yang dipengaruhi angina muson sehingga curah hujan cukup merata setiap tahunnya beragam antara $1.000-2.000$ milimeter per tahun.

Jumlah penduduk Kecamatan Waplau pada akhir tahun 2013 adalah sebanyak 12.367 jiwa, dengan kepadatan penduduk sebesar 25 jiwa/km2. Jika dilihat dalam unit rumah tangga yang mencapai $2.812 \mathrm{KK}$, maka rata-rata setiap rumah tangga beranggotakan 4 jiwa/KK. Desa yang paling banyak rumah tangganya adalah Desa Waeputih sebanyak 408 KK, sedangkan yang terkecil adalah Desa Samalagi sebanyak 107 KK. Berdasarkan data jumlah penduduk pada tahun 2011 sebanyak 11.337 orang dan jumlah penduduk pada tahun 2012 sebanyak 12.367, maka pertumbuhan penduduk Kecamatan Waplau adalah sebesar 0,09 \%, maka Pertumbuhan penduduk Kecamatan Waplau termasuk pertumbuhan tinggi.

Dalam upanya memenuhi kebutuhan sehari hari warga setempat (Lokasi Studi) berbagai aktifitas mata pencaharian dilakukan. Dari sekian banyaknya mata pencaharian yang dilakukan warga, Petani/tukang Kebun merupakan mata pencaharian mayoritas penduduk sebanyak 1.380 orang $(44,76 \%)$, diikuti mata pencaharian nelayan sebanyak 464 orang $(15,05 \%)$. Sedangkan mata pencaharian yang paling sedikit adalah penjahit sebanyak 16 orang $(0,52 \%)$.

Tanggapan masyarakat di sekitar terhadap model pengembangan kawasan transmigrasi pada umumnya mereka mengetahui ada program penempatan transmigrasi. Masyarakat di sekitar lokasi studi mengemukakan komposisi yang cocok untuk program penempatan 
transmigrasi di lokasi studi adalah $50 \%$ penduduk lokal dan $50 \%$ penduduk pendatang. Dengan komposisi tersebut, diharapkan proses pembauran antara pendatang dan penduduk lokal lebih cepat terjadi. Kekurangan dari program transmigrasi menurut penduduk di sekitar lokasi studi antara lain :

- Jatah hidup yang selama ini diberikan dalam program transmigrasi masih dirasakan kurang baik dari segi kuantitas maupun kualitasnya.

- Masih minimnya sarana produksi pertanian yang berkualitas di lokasi transmigrasi.

- Minimnya informasi mengenai teknologi pertanian yang sampai ke lokasi transmigrasi.

Tanggapan masyarakat di sekitar lokasi studi terhadap program penempatan Transmigrasi mengemukakan mendukung sekali, dengan alasan apabila program tersebut dilaksanakan, masyarakat dapat menjadi peserta transmigrasi, dapat menikmati fasilitas yang dibangun oleh pemerintah, dapat meningkatkan pengetahuan tentang cara-cara bercocok tanam, serta dapat meningkatkan kesejahteraan keluarganya.

\section{HASIL DAN PEMBAHASAN}

\section{Karakteristik Model Pengembangan Kawasan Transmigrasi}

Berdasarkan beberapa aspek tata ruang yang dianalisis yang meliputi aksesibilitas lokasi, kondisi fisik lahan, dan kondisi sumber daya air tercatat berbagai hal yang menjadi bahan pengembangan model. Hasil Penilaian Aksesibilitas Lokasi, tercatat bahwa lokasi permukiman transmigrasi SP 1 Waplau berada tidak terlalu jauh Kecamatan Waplau dengan jarak sekitar + 9,0 Km, Akses pemasaran hasil-hasil produksi pertanian cukup mudah dipasarkan. Selanjutnya, hasil penilaian kesesuaian lahan aktual standar rata-rata dapat diuraikan sebagai berikut :
a. SPL 1, SPL 2 dan SPL 4, Rekomendasi penggunaan areal ini untuk diusahakan tanaman pangan padi ladang dan palawija, tanaman tahunan dan tanaman perkebunan ).

b. SPT 3 dan SPL 6, Rekomendasi penggunaan areal ini untuk diusahakan tanaman pangan ( padi ladang dan palawija, tanaman hijuan ternak, tanaman tahunan dan perkebunan ).

c. SPT 5, Rekomendasi penggunaan areal ini untuk diusahakan tanaman palawija , tanaman hijuan ternak dan tanaman tahunan seluas 474,96 ha $(14,63 \%)$.

Selanjutnya hasil penilaian ketersediaan air, ketersediaan air bersih merupakan hal utama bagi permukiman transmigrasi, berdasarkan hasil perhitungan jumlah debit rata - rata mata air Desa Samalagi sebesar 65 Liter/detik dan kebutuhan kebutuhan air bersih minimum per KK ( terdiri 4 orang ) yaitu 60 liter $\mathrm{x}$ 4 jiwa $\times 30$ hari $=7.200$ liter, dapat mencukupi untuk kebutuhan air bersih penduduk transmigran sebanyak $300 \mathrm{KK}$.

\section{Optimalisasi Beban Model Penempatan Transmigran Dalam Model Pengembangan Kawasan Transmigrasi}


Rencana peruntukan daya tampung ditentukan oleh kebutuhan pengembangan bagi pemukiman transmigrasi. Alokasi Lahan per $\mathrm{KK}$ adalah 2,00 Ha dengan perincian Lahan Pekarangan (LP) $=0,25$ Ha, Lahan Usaha I (LU I) $=0,75 \mathrm{Ha}$ dan Lahan Usaha II (LU II) = 1,00 Ha. maka dapat dibentuk satuan pemukiman dengan daya tampung sebesar $300 \mathrm{KK}$. Rincian penggunaan lahan sesuai dengan daya tampung di lokasi studi dapat dilihat pada Tabel 1.

Permukiman penduduk transmigran dengan segala fasilitas pendukungnya paling ideal berada pada kemiringan lahan 0 - $8 \%$, bebas dari bahaya banjir, mempunyai sumber air bersih dan tingkat kesuburan tanah yang memadai, sedangkan iklim dan ketinggian relatif tidak berpengaruh terhadap pemilihan lokasi permukiman. Rencana tata ruang untuk permukiman transmigrasi berupa: (1) Tata Ruang Satuan Pemukiman yang direncanakan dalam satu kelompok, yaitu fasilitas umum desa, terpisah dengan lahan pekarangan., (2) Letak Pusat Desa (PD) relatif linear, dan (3) Peruntukan lahan terdiri dari: Lapis pertama Pusat Desa/Fasilitas Umum, Lapis kedua Lahan Pekarangan dan Lapis Ketiga Lahan Usaha I dan Lahan Usaha II.

Table 1. Peruntukan Lahan

\begin{tabular}{clccc}
\hline \multirow{2}{*}{ No } & \multicolumn{1}{c}{ Jenis Peruntukan } & Km & \multicolumn{2}{c}{ Luas } \\
\cline { 4 - 5 } & & & Ha \\
\hline A. & Yang Dibuka & 75 & $23 \%$ \\
1 & Lahan Pekarangan & 225 & $69 \%$ \\
2 & Lahan Usaha I & 10.5 & $3 \%$ \\
3 & FasilitasUmum & 2.2 & $1 \%$ \\
4 & Kuburan & 5,272 & $2 \%$ \\
5 & Jalan Desa & $4,272 \mathrm{Km}$ & $1 \%$ \\
6 & Jalan Poros & $2,398 \mathrm{Km}$ & 4,796 & $\mathbf{1 0 0 \%}$ \\
\hline & Sub-Total A & $\mathbf{3 2 2 . 7 6 8}$ & \\
\hline B & Lahan Yang Tidak dibuka & 300 & $\mathbf{7 5 \%}$ \\
1 & Lahan Usaha II & 10 & $2 \%$ \\
2 & Pangonan/Penggembalaan & 18.2 & $5 \%$ \\
3 & Tanah Kas desa (TKD) & 74.04 & $18 \%$ \\
4 & Lahan konservasi & $\mathbf{4 0 2 . 2 3}$ & $\mathbf{1 0 0 \%}$ \\
\hline & Sub-Total B & $\mathbf{7 2 5}$ & $\mathbf{1 0 0 \%}$ \\
\hline
\end{tabular}

Sumber : Hasil analisis, 2014 
Pengembangan Pertanian Model Usaha

\section{Transmigran}

Dalam menyusun pengembangan pertanian dalam model usaha transmigrasi, beberapa aspek yang dipertimbangkan diantaranya, keadaan pertanian dilokasi studi, kondisi agroklimat dan kesesuaian lahan, sumber dan ketersediaan tenaga kerja, ketersedian prasarana dan sarana penunjang, tingkat teknologi yang ada dan prospek pemasaran dari komoditi yang akan dikembangkan. Prioritas dalam mengoptimalkan lahan pertanian meliputi Lahan Pekarangan (LP) seluas 0,25 hektar, Lahan Usaha I (LU I) seluas 0,75 hektar, dan Lahan Usaha II (LU II) seluas 1,00 hektar.

Lahan Pekarangan, Lahan seluas 0,25 hektar, selain digunakan untuk rumah, kandang ternak beserta fasilitasnya, juga dimanfaatkan untuk pengembangan tanaman pangan lahan kering dan hortikultura. Pengembangan pertanian yang diusulkan meliputi jenis tanaman, pola tanam dan jadual tanam, jumlah tenaga kerja, faktor-faktor produksi pertanian yang digunakan, perkiraan produksi dengan memperhatikan kesesuaian lahan, dan ketersediaan tenaga kerja.
Lahan Usaha I, Lahan ini diusahakan untuk memenuhi/menambah kebutuhan pangan keluarga, sisanya dapat disisihkan untuk tabungan jangka pendek dan diperdagangkan sampai tingkat kabupaten atau antar propinsi. Jenis komoditi yang diusahakan adalah tanaman pangan seperti padi dan palawija yang diselingi oleh tanaman pisang yang sekaligus perindang.

Lahan Usaha II, Lahan seluas 1 hektar disarankan untuk ditanami tanaman yang mempunyai orientasi ekspor dan merupakan tanaman tahunan/keras atau tanaman yang mempunyai nilai ekonomis dan politis bagi kepentingan negara dan masyarakat. Komoditi Jambu Mete merupakan prioritas untuk dikembangkan di Lahan Usaha II, mengingat tanaman jambu mete mempunyai nilai ekonomis dan termasuk barang tradeable (barang ekspor), ditunjang oleh banyaknya masyarakat di

Data mengenai varietas tanaman, jarak tanam, umur tanaman, dan perkiraan produksi, tiap jenis tanaman disajikan pada Tabel 2.

Table 2. Usulan varietas tanaman padi, palawija, hortikultura, dan tanaman keras

\begin{tabular}{rllrr}
\hline No & \multicolumn{1}{c}{$\begin{array}{c}\text { Jenis } \\
\text { Tanaman }\end{array}$} & Varietas & \multicolumn{1}{c}{$\begin{array}{c}\text { Umur } \\
\text { (hari) }\end{array}$} & $\begin{array}{r}\text { Potensi } \\
\text { Produk } \\
\text { (ton/ha) }\end{array}$ \\
\hline 1 & Padi (Oryza sativa L) & Situ Bagendit & 120,00 & $3,00-5,00$ \\
2 & Jagung (Zea mays L.) & Sukmaraga & 110,00 & 6,00 \\
3 & Ubi Kayu (Manihot utilissima Pohl) & ADIRA 4 & 300,00 & 35,00 \\
4 & Kacang Tanah (Arachis hypogaea) & Gajah & 90,00 & 2,20 \\
\hline
\end{tabular}




\begin{tabular}{|c|c|c|c|c|}
\hline 5 & Kacang Hijau (Vigna radiatus) & Walet & 70,00 & 1,50 \\
\hline 6 & Rambutan (Nephelium sp.) & Lebak Bulus & 4 tahun $*)$ & 0,40 \\
\hline \multirow[t]{2}{*}{7} & Durian (Bombaceae sp.) & Ligit & 5 tahun $*)$ & $400 * *)$ \\
\hline & $\begin{array}{l}\text { Nangka (Artocarpus heterophyllus } \\
\text { Lamk) }\end{array}$ & Lokal & 8 tahun $*)$ & $50 * *)$ \\
\hline \multirow[t]{2}{*}{9} & Mangga (Mangifera spp.) & $\begin{array}{l}\text { Mangga Cengkir } \\
\text { Indramayu }\end{array}$ & 5 tahun $*)$ & $300 * *)$ \\
\hline & Jeruk (Citrus microcarpa L.) & $\begin{array}{l}\text { Siam Varietas } \\
\text { Pontianak }\end{array}$ & 4 tahun $*)$ & $100-200 * *)$ \\
\hline 11 & Kelapa Hibrida (Cocos nucifera) & KHINA - 4 & 4 tahun $*)$ & $104 * *)$ \\
\hline 12 & Pisang (Musa sapientum L. Kuntze) & Agung Semeru & 1 tahun $*)$ & $1 * *)$ \\
\hline \multirow[t]{2}{*}{13} & Jambu Mete (Hevea brasiliensis) & Lokal & 4 tahun $*)$ & 2,28 \\
\hline & Kayu Putih (Melaleuca cajuputi) & Lokal & 5 tahun $* * *)$ & 20 \\
\hline
\end{tabular}

Table 3. Alternatif tindakan penanggulangan dampak

\begin{tabular}{|c|c|c|c|}
\hline No & Komponen & $\begin{array}{c}\text { Dampak Penting } \\
\text { Hipotetik }\end{array}$ & Alternatif Tindakan \\
\hline \multirow[t]{6}{*}{1.} & Fisik - Kimia & Iklim & Penghijauan \\
\hline & & Kualitas Udara & $\begin{array}{l}\text { Minimalisasi Penggunaan Alat berat, } \\
\text { Penghijauan }\end{array}$ \\
\hline & & Erosi & $\begin{array}{l}\text { Minimalisasi pengolahan tanah, Budidaya } \\
\text { tanaman tahunan (mede, kopi) }\end{array}$ \\
\hline & & Kesuburan Tanah & Mempertahankan top soil, Pemupukan \\
\hline & & Kualitas Air Permukaan & Penghijauan \\
\hline & & Perubahan Bentang Alam & Mengurangi cut and fill \\
\hline \multirow[t]{8}{*}{2.} & Biologi & Flora & \\
\hline & & - Vegetasi asli & Konservasi, Pelestarian vegetasi asli \\
\hline & & - Potensi tegakan & $\begin{array}{l}\text { Penanaman pohon besar yang mempunyai nilai } \\
\text { ekonomis (jati dll) }\end{array}$ \\
\hline & & Fauna & \\
\hline & & - Habitat asli & Pelestarian fauna \\
\hline & & - Keaneka ragaman fauna & Pelestarian fauna \\
\hline & & - Perubahan status fauna & $\begin{array}{l}\text { Menjaga keseimbangan populasi fauna yang } \\
\text { mempunyai potensi menjadi hama tanaman }\end{array}$ \\
\hline & & - Por & Pelestarian fauna \\
\hline \multirow[t]{3}{*}{3.} & Sosial & Konflik sosial & $\begin{array}{l}\text { Pemilihan TPA disesuaikan dengan usulan } \\
\text { masyarakat setempat }\end{array}$ \\
\hline & & Akulturasi dan Asimilasi & $\begin{array}{l}\text { Penyuluhan peningkatan kesadaran terhadap } \\
\text { keberadaan TPA }\end{array}$ \\
\hline & & Kepemilikan lahan & Sosialiasi program transmigrasi \\
\hline \multirow[t]{2}{*}{4.} & Ekonomi & $\begin{array}{l}\text { Kesempatan kerja dan } \\
\text { peluang usaha }\end{array}$ & $\begin{array}{l}\text { Peningkatan sarana dan prasarana perekonomian } \\
\text { (transportasi, pasar, lembaga ekonomi/KUD) }\end{array}$ \\
\hline & & Pendapatan rumah tangga & Peningkatan SDM, pelatihan \\
\hline
\end{tabular}




\section{Penanganan Dampak Model}

Dalam upaya penanganan terhadap penanggulanan dampak yang mungkin muncul pada aspek lingkungan fisik, biologi, sosial dan ekonomi perlu dicermati beberapa masukan penanganan yang dapat dilakukan nantinya seiring dengan adanya pembukaan lahan SP 1 Waplau Desa Samalagi Kecamatan Waplau kabupaten Buru Provinsi Maluku. Dimana upaya yang dilakukan secara rinci disajikan pada Tabel 3.

\section{KESIMPULAN DAN SARAN}

\section{Kesimpulan}

Berdasarkan hasil analisis dan pembahasan serta identifikasi masalah dalam penelitian ini, dapat disimpulkan sebagai berikut :

1. Karakteristik model yang meliputi aksesibilitas lokasi, kondisi fisik lahan, dan kondisi sumber daya air tercatat memberikan suatu gambaran kemampuan sumberdaya alam dalam menunjang pengembangan kawasan transmigrasi di Kabupaten Buru

2. Berkaitan dengan Optimalisasi Model Penempatan Transmigran Dalam Model Pengembangan Kawasan Transmigras, maka rencana yang tepat peruntukan daya tampung ditentukan oleh kebutuhan pengembangan bagi pemukiman transmigrasi. Alokasi Lahan per KK adalah 2,00 Ha dengan perincian Lahan Pekarangan (LP) $=$ 0,25 Ha, Lahan Usaha I (LU I) = $0,75 \mathrm{Ha}$ dan Lahan Usaha II (LU II) $=$ 1,00 Ha. maka dapat dibentuk satuan pemukiman dengan daya tampung sebesar $300 \mathrm{KK}$.

3. Pengembangan Pertanian Model Usaha Transmigrasi, dapat dilakukan dengan prioritas dalam mengoptimalkan lahan pertanian meliputi Lahan Pekarangan (LP) seluas 0,25 hektar, Lahan Usaha I (LU I) seluas 0,75 hektar, dan Lahan Usaha II (LU II) seluas 1,00 hektar.

Berkaitan dengan penanganan model, perlu dilakukan upaya alternatif tindakan terhadap dampak penting hipotetik

\section{DAFTAR PUSTAKA}

Alsa, Asmadi. 2004. Pendekatan Kuantitatitatif dan Kualitatif serta Kombinasinya dalam Penelitian Psikologi. Yogykarta: Pustaka Pelajar.

Anwar A. 2005. Ketimpangan Pembangunan Wilayah dan Perdesaan. Tinjauan kritis. Bogor : P4W Press Bogor.

Badan Pusat Statistik Kabupaten Buru. 2013. Produk Domestik Regional Bruto Kabupaten Buru Menurut Lapangan Usaha. Kabupaten Buru : BPS Kabupaten Buru.

Badan Pusat Statistik Kabupaten Buru. 2014. Statistik Kecamatan Waplau 2014. Kabupaten Buru : BPS Kabupaten Buru.

Badan Pusat Statistik Kabupaten Buru. 2014. Buru Dalam Angka 2014. Kabupaten Buru : BPS Kabupaten Buru. 
Badan Pusat Statistik Kabupaten Buru. 2014. Indikator Kesejahteraan Rakyat Kabupaten Buru Tahun 2014. Kabupaten Buru : BPS Kabupaten Buru.

[Depnakertran] Departemen Tenaga Kerja dan Transmigrasi. 2007. Nilai Tambah Itu bernama KTM. http://www.nakertrans.go.id/new sdetail.php?id=285 [01-03-2007]

[Depnakertran] Departemen Tenaga Kerja dan Transmigrasi. 2000. Undang-undang Nomor 15 Tahun 1997 tentang Ketransmigrasian. Jakarta. Depnakertran

[Depnakertran] Departemen Tenaga Kerja dan Transmigrasi. 2000. Peraturan Pemerintah Nomor 2 Tahun 1999 tentang Pelaksanaan Transmigrasi. Jakarta. Depnakertran

[Depnakertran] Departemen Tenaga Kerja dan Transmigrasi. 2000. Keputusan Menteri Transmigrasi Nomor 124/Men/1990 tentang Pola Pemukiman dan Pengembangan Usaha Transmigrasi. Jakarta:

Depnakertran.

Direktorat Jendral Pembinaan Pengembangan Masyarakat dan Kawasan Transmigrasi. 2006. Kota Terpadu Mandiri. Jakarta: Departemen Tenaga Kerja dan Transmigrasi.

Direktorat Perencanaan Teknis Pengembangan Masyarakat dan
Kawasan. Dirjen PPMKT Departemen Tenaga Kerja dan Transmigrasi. 2006. Bahan Ekspose Pembanggunan Kota terpadu Mandiri Kabupaten Tulang Bawang Propinsi Lampung. Jakarta: Depnakertrans.

Direktorat Jenderal Tanaman Pangan. 2012. Rencana Strategis Direktorat Jenderal Tanaman Pangan Tahun 2010-2014. Jakarta : Direktorat Jenderal Tanaman Pangan - Kemenrian Pertanian.

Friedmann J. 1997. Judul : Basic Needs, Agropolitan Development, And Planning From Below. World Development. Pergamon Press Ltd. 1979. Great Britain. Vol. 7 pp. 607-613.

Gaspersz, Vincent. 1991. Metode Perancangan Percobaan. Bandung : Armico.

Hardjowigeno dan Widiatmaka. 2001. Kesesuaian Lahan dan Perencanaan Tata Guna Tanah. Departemen Ilmu Tanah dan Menejemen Sumber Daya Lahan. Bogor: Fakultas Pertanian, Institut Pertanian Bogor.

Heeren, H. J. 1979. Transmigrate In Indonesia. Jakarta. Gramedia.

Jabbar, Ramadhan. Hamid dan Rofiq Ahmad. 1993. Transmigrasi Harapan dan Tantangan. Departemen Transmigrasi RI. Jakarta. 
Kecamatan Waplau. 2012. Data Administrasi Kecamatan dan Potensi Kecamatan Waplau. Kecamatan Waplau Kabupaten Buru.

Kecamatan Waplau. 2012. Renstra Kecamatan Waplau Tahun 2012.

Kecamatan Waplau Kabupaten Buru.

Kerlinger, Fred N. 2004. Asas-asas Penelitian Behavioral. Yogyakarta : UGM Press.

Kolopaking L.M. 2007. Pengembangan Kawasan Perdesaan dan Kota Transmigrasi Mandiri Berbasis Pemberdayaan Komunitas. Jakarta: Depnakertrans.

MacAndrew, Colin. \& Rahardjo. 1979. Pemukiman di Asia Tenggara dan Transmigrasi di Indonesia. Yogyakarta : UGM. Gadjah Mada University Press.

Manuwijaya, Mirwanto, 2004, Mengenal dan Memahami Transmigrasi, Pustaka Sinar Harapan, Jakarta.

Mikkelsen, Britha. 2001. Metode Penelitian Partisipatoris dan Upaya-Upaya Pemberdayaan. Terjemahan. Jakarta : Yayasan Obor Indonesia.

Moleong, Lexy J, 1995, Metodologi Penelitian Kualitatif, Bandung: Remaja Rosdakarya.

Muhadjir. Noeng. 2002. Metodologi Penelitian Kualitatif. Yogyakarta : Rake Sarasin.
Mulyana, Deddy. 2003. Metodologi Penelitian Kualitatif : Paradigma Baru Ilmu Komunikasi dan Sosial lainnya. Bandung : PT.Remaja Rosdakarya.

Nazir, Moh. 1983. Metode Penelitian. Jakarta :PT. Ghalia Indonesia.

Peraturan Pemerintah Nomor 25 tahun 2000 tentang Kewenangan Pemerintah Pemerintah Propinsi Sebagai Daerah Otonom.

Peraturan Pemerintah Nomor 2 tahun 1999 tentang Penyelenggaraan Transmigrasi. Departemen Transmigrasi. Jakarta

Priyono dan Siti Fatimah, 2007. Konsep Kawasan Transmigrasi Lokasi Pemukiman Transmigrasi (LPT) dan Wilayah Pengembangan Transmigrasi (WPT) sebagai alat Pembangunan Daerah. Jakarta : Depnakertrans.

Pusat Data dan Informasi Ketransmigrasian. 2004. Membangun Daerah Bersama Transmigrasi. Jakarta Depnakertran.

Soehartono, Irawan. 2000. Metode Penelitian Sosial : Suatu Teknik Penelitian Bidang Kesejahteraan Sosial dan Ilmu Sosial lain. Bandung : PT Remaja Rosdakarya.

Singarimbun, Masri dan Effendi, Sofian. 1995. Metode Penelitian Survey. Jakarta : PT Pustaka LP3ES. 
Sumarjo. 2004. Transmigrasi Tarigan R. 2005. Perencanaan Menyongsong Era Otonomi Pembangunan Wilayah. Edisi Daerah dan Globalisasi Revisi. Jakarta: Bumi Aksara.

Ekonomi. Makalah disampaikan pada ceramah dan Diskusi/Temu

Todaro, Michael P. 2000. Pembangunan Pakar Ketransmigrasian. Jakarta : Pusat Data dan Informasi Ketransmigrasian.

Sunaryadi A. 2005. Pemukiman Transmigrasi Cikal Bakal Agropolitan. Jakarta Depnakertrans. Info Ketransmigrasian. Vol I No.3 Juni 2005; Hal 4.

Suparno, E. 2006 Paradigma Baru Sistem Penyelenggaraan Transmigrasi. www.depkominfo.go.id.

Februari 2007)

Suparno, Erman. 2007. Pidato Peringatan Hari Bhakti Transmigrasi Ke 57 Tahun 2007. Diakases tanggal $27 \quad$ Desember 2010. http://bto.sisfo.net. Ekonomian Dunia Ketiga. Alih Bahasa Han Munandar. Jakarta: Penerbit Erlangga.

Undang Undang Nomor 15 tahun 1997 tentang Ketransmigrasian.

Undang Undang Nomor 32 tahun 2004 tentang Pemerintah Daerah

Undang-undang Nomor 29 Tahun 2009 sebagai pengganti Undangundang Nomor 15 tahun 1997 tentang ketransmigrasian.

Utomo M. 2005. Tinjauan Kritis Kebijakan dan Implementasi Penyelenggaraan Transmigrasi. Makalah disampaikan pada Semiloka Transmigrasi dan Penguatan NKRI.[30 Novmber 2005] Jakarta.

Widodo, T. 2008. Metode Penelitian Kuantitatif. Solo : UNS Press.

* Dosen Program Studi Agribisnis, FST UIN Syarif Hidayatullah Jakarta (Email: achmad_tj@yahoo.com) 